\title{
El primer cine soviético en Argentina El Comité Central de Ayuda al Proletariado Ruso y la distribuidora Russ Film (1922-1927)
}

La información que circula sobre la distribución en Argentina de la cinematografía soviética, una de las más importantes del período mudo, es sumamente escasa y fragmentaria. 'De hecho, algunas investigaciones que se proponen historizar desde una perspectiva amplia su recepción en América Latina señalan que las primeras películas soviéticas se exhibieron en nuestro país a fines de la década de $1920 .{ }^{2}$ Pero, en realidad, la llegada del cine de la Rusia revolucionaria se remonta a comienzos de esa década.

Para analizar la etapa inicial de la distribución del cine soviético en Argentina tenemos que referirnos a una organización que no tendría en primera instancia una relación directa con el ámbito cinematográfico: el Comité Central de Ayuda al Proletariado Ruso con sede en Capital Federal. ${ }^{3}$ Esta organización estaba dedicada a ayudar a paliar la hambruna que azotaba algunas regiones de Rusia desde 1921 y a fomentar la reconstrucción económica de ese país. Su actividad se enmarca en una campaña a nivel mundial por los hambrientos de Rusia, que había sido diseñada, como señala Daniela Lucena, por la Internacional Comunista. ${ }^{4}$

A ese Comité Central respondía una red de comités locales, subcomités y diversos grupos de adherentes que se dedicaban a recaudar fondos a través de la organización de festivales, exposiciones, conferencias, rifas, venta de diversos productos $y$

* Biblioteca y Centro de Documentación y Archivo del Instituto Nacional de Cine y Artes Audiovisuales

1 Esta investigación fue presentada en las IX Jornadas de Historia de las Izquierdas organizadas por el $\mathrm{CeDInCl}$ en 2017. Quisiera agradecer muy especialmente a Natalia Bustelo y a Hernán Villasenin por aportar sugerencias y modificaciones al texto original. También resultó importante la colaboración de Matt Losada, Lucas Domínguez Rubio y Daniela Oulego, quienes contribuyeron con algunos artículos fundamentales para este trabajo.

2 Ver Sarah Ann Wells, "Parallel modernities?: The first reception of soviet cinema in Latin America", en Cosmopolitan Film Cultures in Latin America, 1896-1960, editado por Rielle Navitski y Nicolás Poppe, Indiana University Press, Bloomington, Indiana, 2017, pp. 151-175.

3 Según el historiador Hernán Camarero su denominación inicial había sido Comité de Ayuda al Pueblo Soviético. Hernán Camarero, Tiempos rojos. El impacto de la Revolución rusa en la Argentina, Buenos Aires, Sudamericana, 2017, p. 289.

4 Daniela Lucena, "Por el hambre en Rusia. Una ofrenda de los artistas argentinos al pueblo de los soviets", en Sociedad, n² 26, 2007. donaciones. ${ }^{5}$ Parte de lo recaudado se enviaba al Comité Internacional con sede en Berlín, el Internationale Arbeiter-Hilfe (IAH), que había sido conformado a instancia del activista comunista de origen alemán Willi Münzenberg. Como indica Natalia Bustelo, el periodista y profesor universitario alemán Alfons Goldschmi$\mathrm{dt}$, uno de los fundadores de Internationale Arbeiter-Hilfe, fue el representante de la Internacional Comunista enviado a la Argentina en abril de 1922 para coordinar la acción del Comité Central de Ayuda al Proletariado Ruso. ${ }^{6}$ Si bien ese Comité estaba íntimamente ligado al Partido Comunista argentino (anteriormente denominado Partido Socialista Internacional), no era parte de una actividad específicamente partidaria, ya que permitía una mayor apertura a diversos sectores sociales.

A partir de 1922, la exhibición de películas entró dentro la órbita de esta organización, que se encargó de gestionar la proyección de los primeros documentales en favor de la Unión Soviética que llegaron a nuestro país a través de Alemania por intermedio del Internationale Arbeiter-Hilfe (IAH). Según el folleto Erobert den film!, escrito por Willi Münzenberg, durante 1922 se exhibieron en Argentina los cortometrajes sobre la hambruna en Rusia Hunger in soviet Russia y The Volga down. Al año siguiente se proyectó la primera película de ficción soviética en nuestro país. En un festival organizado por el Comité Local de Ayuda al Proletariado Ruso de La Plata se exhibió, el viernes 6 de julio a las 20:30 hs. en el Select Cine (La Plata), el film El milagro del soldado Iván, ${ }^{7}$ "cuento de [León] Tolstoi adaptado al cine en Rusia".

Pero el Comité Central de Ayuda al Proletariado Ruso decidió

5 Entre otros adherentes, podemos mencionar el Comité Femenino de Ayuda Pro Niños Rusos, Comité Infantil de Amistad con los Niños Rusos, Comité Pro Ayuda a los Estudiantes Rusos, y a la Agrupación de Ebanistas Pro Adopción de Niños y Ayuda Constructiva a Rusia.

6 Natalia Bustelo, "Las lecciones de Alfons Goldschmidt en la Reforma Universitaria: economía marxista y radicalización estudiantil (1922)", Actas de las VI Jornadas del Movimiento Estudiantil, Buenos Aires, 2016.

7 En esa primera exhibición fue presentado con el título El sueño del soldado Iván

8 Se exhibió junto con una película cómica de Charles Chaplin y el film nacional Los muertos, basado en la obra teatral de Florencio Sánchez. En el curso de esa "velada" el militante Augusto Pellegrini dio una conferencia titulada "Lo que he visto en Rusia" y se entonaron canciones revolucionarias (La internacional, 6/7/1923). 
comercializar las primeras producciones soviéticas en las salas tradicionales a través de la empresa Mundial Film. Esta distribuidora, propiedad del empresario Alejandro Gómez, estaba ubicada en Montevideo 17 (Capital Federal) y se dedicaba a exhibir en el mercado interno y en los países limítrofes principalmente la producción cinematográfica italiana. Mundial Film estrenó el viernes 20 de julio de 1923 en los cines céntricos Etoile y Standard Theatre el primer documental de propaganda soviético exhibido comercialmente en nuestro país: Un poco de luz sobre la Rusia roja (Piatilietie sovjetskoi Rossii, 1922), "una crónica gráfica de la vida de la Rusia actual, tomada con motivo de celebrarse el quinto aniversario de la revolución comunista y el cuarto congreso de la Internacional Comunista". ${ }^{9}$ Dada la dificultad de acceder a este film, transcribimos a continuación un resumen de su contenido: ${ }^{10}$

1. Petrogard y Moscú, después de la revolución. Panorama. 2. Ferrocarriles rusos. La estación de Nicolaiewsky. 3. Llegada de los delegados internacionales. 4. El pueblo en la plaza Nicolaieff. 5. Los comisarios del pueblo. 6. Mitin monstruo en Petrograd. 7. El instinto Smolny, sede del Soviet. 8. Teatro de la Opera de Petrogard, sala de sesiones del Congreso. 9. La guardia roja ante el Smolny. 10. Desfile de la infantería roja ante el Palacio de Invierno. 11. Demostración de los cosacos rojos del Don. 12. La marinería roja de la guarnición de Kronstadt. 13. Desfile de la artillería y de los tanques. 14. Desfile de los carros alegóricos. 15. En el campo de Marte, cementerio de la Revolución. 16. Petrogard nocturno. 17. Moscou. El Kremlin. La Plaza Roja. Los tranvías. 18. Monumento alegórico "Al trabajo". 19. Arenga de Trotzky. 20. Juramento de los reclutas del Ejército Rojo. 21. Las usinas exponen productos. 22. Los dirigentes del Gobierno en la sala del trono de los Zares. 23. Zinovieff, Bujarín, Munzenbert, Bela Khun y Kusmin. 24. El estado mayor del Ejército Rojo. 25. Carlos Radek y León Kameneff. 26. Los delegados internacionales. 27. La delegación de la República Argentina. 28. Fotografía de Lenin: enfermo durante estos sucesos. 29. El pueblo festeja el quinto aniversario de la Revolución."

El estreno de Un poco de luz sobre la Rusia roja fue promocionado en la revista cinematográfica La película, destinada principalmente a los exhibidores que podían eventualmente alquilar el film, pero también en las páginas del periódico comunista La internacional, entre cuyos lectores se encontraban parte de los potenciales espectadores. ${ }^{12}$

Sobre este film La película señaló que fue un éxito debido a que "la vida de la Rusia actual para la mayoría de las gentes resulta

\section{$9 \quad$ La película, $n^{\circ} 354,5 / 7 / 1923$.}

10 En el Festival Internacional de Cine de Berlín de 2012 se exhibió una copia de esta película.

11 La película, $n^{\circ} 354,5 / 7 / 1923$.

12 Ver publicidades en La internacional, 20/7/1923 y 21/7/1923. un misterio".?3 Ese fuerte interés del público argentino por los acontecimientos de la Rusia bolchevique se puede desprender también de las publicidades de otras películas contemporáneas que abordaban esa temática. Es el caso del film de ficción Bavú, que era promocionado entre los propietarios de las salas de la siguiente manera: "si Ud. conoce la psicología de su público indudablemente sabrá la curiosidad que tiene por los episodios de la RUSIA ROJA [...] y le proporcionará a Ud. MUCHO DINERO".14

Es que esa temática recurrente en la prensa de la época y en la literatura de consumo había adquirido por ese entonces sumo protagonismo debido a múltiples factores. Por un lado, es importante destacar la influencia que tuvo la revolución bolchevique en la política argentina, muy especialmente entre 1918 y 1922 en el marco de intensificación de la lucha obrera. Por otro, porque se trató de un período convulsionado de la vida en Rusia, caracterizado por el reciente triunfo bolchevique en la guerra civil, la crisis económica, las revueltas internas y la dramática hambruna en la región del Volga que había provocado campañas de ayuda a nivel internacional.

Ahora bien, la revista La película también dio cuenta de la orientación del documental Un poco de luz sobre la Rusia roja, ya que indicó que "en esta cinta es fácil ver cómo funciona el estado bolsheviqui (sic), el que se desenvuelve en forma normal, dando una impresión que desecha los juicios fantásticos que tiene la mayoría de la gente de la Rusia roja". 15

Esos "juicios fantásticos" a los que aludía el redactor seguramente tenían que ver con una imagen de la Revolución signada por el caos, el hambre, la barbarie y el terror. En contraposición, si nos atenemos al sumario, este documental propagandístico proyecta la visión de una Rusia que emerge incólume y fortalecida de ese contexto de crisis que está presente en "fuera de campo". La exaltación del poder político y militar bolchevique durante la celebración del quinto aniversario de la Revolución (las figuras políticas principales, la artillería, los tanques, el desfile de los guardias rojos, etc.), sostenido por la movilización de masas y la ocupación simbólica de los espacios de la reacción ("Los dirigentes del Gobierno en la sala del trono de los Zares" / "desfile de la infantería roja ante el Palacio de Invierno") reafirma el triunfo frente a los "blancos" en la guerra civil, que se concretó un mes antes del inicio de la filmación del documental. Pero esa exaltación del poderío bolchevique opera también sobre las rebeliones internas recientes (Kronstadt) a través de imágenes simbólicas que remiten a la instauración del "orden" ("La marinería roja de la guarnición de Kronstadt"). La visión de una Unión Soviética moderna y en desarrollo (ferrocarriles, tranvías, usinas) funciona como contrapartida de la imagen de un país inmerso en la crisis

\footnotetext{
13 La película, $n^{\circ} 357,26 / 7 / 1923$

14 Excelsior, $n^{\circ} 492,15 / 8 / 1923$

15 La película, $n^{\circ} 357,26 / 7 / 1923$
} 
económica y el hambre. Pero también, en el film, esa fortaleza se expresa a través de la influencia que ejerce la Unión Soviética más allá de sus fronteras, ya que se constituye en el espacio central al que peregrinan los delegados de todo el mundo, incluso de países remotos como Argentina, para asistir a la Internacional Comunista en Moscú. Es en este punto donde el film opera dentro del espectro de las tendencias de izquierdas que adhieren en Argentina a la Revolución Rusa como es el caso del anarco-bolcheviquismo, el Partido Comunista, sectores del sindicalismo revolucionario y algunos grupos del Partido Socialista. ${ }^{16}$ Se trataba de un espectro heterogéneo que incluía una disputa entre sectores - desde hacía varios años - para ser reconocidos como los interlocutores principales en nuestro país de la Internacional Comunista, con la autoridad política y el financiamiento económico que eso implicaba. El film mostraba a "la delegación de la República Argentina" integrada en 1922 exclusivamente por miembros del Partido Comunista, lo que terminaba por confirmar que ese sector era el referente principal para la Unión Soviética.

Por último, este film financiado por Internationale Arbeiter-Hilfe, ofició de propaganda implícita de su fundador y miembro de la Internacional Comunista, Willi Münzenberg, a quien se le otorga en el documental un lugar de relevancia a la par de dirigentes fundamentales como Zinóviev y Bujarin.

Ahora bien, esos "juicios fantásticos" a los que aludía el comentario de la revista La película no sólo se construían por medio de la prensa y la literatura, sino también a través del propio medio cinematográfico, en el que el film Un poco de luz... buscaba intervenir.

Por ejemplo, en 1922 la distribuidora argentina Sociedad General Cinematográfica estrenó La Rusia roja, una "actualidad" de la productora francesa Gaumont. Este documental, que mostraba a los principales líderes de la revolución soviética, las movilizaciones populares y los desfiles del Ejército Rojo, era presentado como carente de "tendencia particular o interesada".17

Sin embargo, en la secuencia final denunciaba el terror bolchevique a través de las siguientes escenas: "los burgueses de Odessa, custodiados por las tropas rojas, ejecutan trabajos forzados [...] la casa de ejecuciones del tribunal de Kiev;

16 Ver Natalia Bustelo, "Entre el entusiasmo ante las noticias insurreccionales y la discusión doctrinaria. Las primeras ediciones bolcheviques argentinas (1918-1924)", en Horacio Tarcus (dir.) y Ezequiel Saferstein (ed.), Edición y revolución. Las editoriales de izquierda en Argentina Buenos Aires, Ubú Ediciones (en prensa); Víctor Jeifets, "La derrota de Los 'Lenins argentinos': La Internacional Comunista, el Partido Comunista y el movimiento obrero de Argentina, 1919-22", en Pacarina del Sur, Ciudad de México, $n^{\circ}$ 6, enero-marzo de 2011; Hernán Camarero, Tiempos rojos. El impacto de la Revolución rusa en la Argentina, Buenos Aires, Sudamericana, 2017.

17 Excelsior, $n^{\circ}$ 410, 18/1/1922. A su vez, la publicidad en Imparcial film, $\mathrm{n}^{\circ}$ $144,21 / 1 / 1922$ indica que "esta película ha sido hecha desde un punto de vista informativo, apartándose en absoluto de toda preferencia". la piel de un ejecutado (descuartizado en vida); vestigios del pasaje de las tropas de represión; ruinas de una fábrica incendiada; victimas...; identificación de cadáveres por los deudos; disponiéndose a sepultar a los muertos".18

Por lo tanto, podemos pensar el título Un poco de luz sobre la Rusia roja como una respuesta dentro del mercado de exhibición argentino al documental de Gaumont, como una forma de echar "luz" sobre esa "Rusia roja" presuntamente tergiversada. Más aún, si tenemos en cuenta que el título elegido inicialmente por Mundial Film para su estreno era Cinco años de gobierno de los soviets, ${ }^{19}$ que se correspondía con su denominación original Piatilietie sovjetskoi Rossii (El quinto aniversario de la Rusia soviética) y con su título en alemán, Fünf Jahre Sovjet-Rußland.

A su vez, la exhibición comercial de Un poco de luz sobre la $\mathbf{R u}$ sia roja se inscribió en el marco de la distribución nacional de los primeros documentales propagandísticos de tendencias políticas antagónicas al comunismo, como es el caso de Fascismo. Este film, que exaltaba "la marcha triunfal de los camisas negras de Nápoles a Roma llevando al poder a Mussolini", ${ }^{20}$ fue estrenado en abril de 1923 por la Cinematografía Argentina Federico Valle. Su proyección había provocado protestas y conflictos en varios cines de Capital Federal, ${ }^{21}$ ciudad que poseía un alto componente inmigratorio de origen italiano.

\section{Russ Film: la primera distribuidora argentina de cine soviético}

A pesar de que la Mundial Film había anunciado el inminente estreno de otras películas soviéticas, el Comité Central de Ayuda al Proletariado Ruso informó que las películas "que fueron alquiladas a una empresa cinematográfica pasan de nuevo bajo la administración del Comité, quien las estrenará por propia cuenta y a beneficio de la obra general que realiza".22 A comienzos de agosto de 1923 se constituyó la primera empresa de nuestro mercado especializada en cine soviético, Russ Film. Fue presentada en la prensa de izquierda como una sociedad cinematográfica anexa al Comité Central Obrero de Ayuda al Proletariado Ruso, ${ }^{23}$ o bien como la "Sucursal de la Sociedad Anónima Industrial Comercial 'Ayuda Obrera Internacional a la Rusia Sovietista"'. ${ }^{24}$ De hecho, Russ Film tenía el mismo domicilio comercial que el Comité Cen-

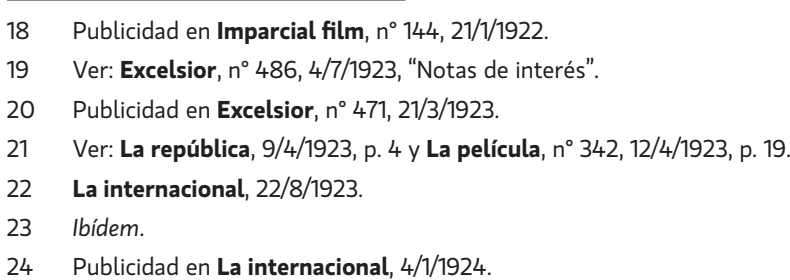


tral, en Sarmiento 2616, y contaba con una sucursal en Rosario (prov. de Santa Fe), en la calle Sarmiento $880 .^{25}$

La Russ Film, entonces, se constituyó en una empresa comercial que poseía oficinas en los dos centros principales del mercado cinematográfico argentino (Capital Federal y Rosario) y publicitó su oferta de películas en las revistas del gremio cinematográfico destinadas a los dueños de las salas. En el propio diario comunista La internacional se hace un llamado a potenciar la exhibición comercial de las producciones de Russ Film al indicar que "los compañeros deben exigir, en los biógrafos que frecuentan, las exhibiciones de estas cintas". ${ }^{26}$

El 22 de agosto de 1923, Russ Film estrenó Alma de mujik (Polikushka, 1922) del cineasta Alexander Sanin. Esta adaptación de un relato de León Tolstoi narraba la trágica historia de un campesino signado por la miseria y la servidumbre durante la época de los zares.

Poco tiempo después, el jueves 6 de septiembre, en el cine Enna Victoria (Capital Federal), Russ Film reestrenó el documental Un poco de luz sobre la Rusia roja. En el transcurso del mes de octubre exhibió comercialmente El milagro del soldado Iván (Chudotvorets, Alexander Panteleev, 1922), una comedia de "carácter antirreligioso", 27 promocionada como la adaptación de una obra de Tolstoi, y el largometraje documental La Rusia sovietista, donde se muestran "cuadros e impresiones de la Rusia actual". ${ }^{8}$ Durante diciembre estrenó el cortometraje Cómo se educan los niños en Rusia, una "interesante vista por la que se puede conocer cómo prepara Rusia a los nuevos ciudadanos de la República Proletaria"29 y el largometraje dramático Yola (Wladyslaw Starewicz, 1920), basado en una leyenda medieval rusa. ${ }^{30}$ Este conjunto de films formaban parte de la oferta principal de esta distribuidora, que eran presentados bajo la denominación de "cintas de carácter social".31

A partir de marzo de 1924, la Russ Film amplió su programa de exhibición con una serie de películas que presentaban varias

25 A partir de marzo de 1924, la distribuidora santafesina Circuito Norte se encargó de comercializar las producciones de la Russ Film (ver La capital, 15/3/1924)

26 La internacional, 26/8/1923.

27 Publicidad en Excelsior, $n^{\circ}$ 520, 27/2/1924.

28 Ibídem.

29 Publicidad en Excelsior, n ${ }^{\circ}$ 520, 27/2/1924. Entre las películas distribuidas por Internationale Arbeiter-Hilfe figuraban los cortometrajes La madre y el niño en la Rusia soviética y Casas de niños y crianza en la Rusia soviética. Es muy probable que Cómo se educan los niños en Rusia sea alguno de estos films o bien la conjunción de ambos.

30 Dentro del programa de la Russ Film también figuraba un documental sobre la hambruna en Rusia titulado Volga, que se distribuyó en circuitos alternativos al de las salas comerciales. En 1924, Excelsior, $n^{\circ} 524$, 26/3/1924, anunció que "en breve" Russ Film iba a estrenar en nuestro país la película de los funerales de Lenin. Sin embargo, no hemos podido confirmar su exhibición

31 Ver publicidad en La película, n 418, 25/9/1924 características llamativas. Por un lado, dentro de las "cintas de carácter social" incorporó dos películas dramáticas del cineasta ruso Yakov Protazanov, dentro de su oferta de películas soviéticas, sin aclarar que tienen la particularidad de haberse realizado en 1917, con anterioridad a la revolución bolchevique. La primera, El padre Sergio (Otest Sergiy), inspirada en un relato de León Tolstoi, narraba la historia de un iracundo militar de la guardia del palacio real que, a raíz de un desengaño amoroso y de su decepción por el zar, tomaba los hábitos, para luego caer en la "tentación" de la lujuria. La segunda, Basta de sangre (¡Ne nado krovi!), ${ }^{2}$ abordaba un "episodio de la revolución rusa de $1905^{\text {"33 }}$ desde la perspectiva de una joven de alta sociedad que se rebela contra su clase para asumir un activismo político contra el régimen zarista. Ambos films eran, en realidad, reestrenos, ya que se habían distribuido en nuestro país con anterioridad. ${ }^{34}$

Por otro lado, bajo el rótulo de "otras cintas", ${ }^{35}$ Russ Film promocionó una serie de películas complementarias al programa principal, entre las que se encuentran algunas realizadas por exiliados rusos que escaparon de la revolución bolchevique. Es el caso de El ordenanza (1921) y Décimo quinto preludio de Chopin (1922), dirigidas por Víctor Tourjansky durante sus primeros años de exilio en Francia, y de El diputado morfinómano (Chlen parlamenta, 1919), ${ }^{36}$ filmada, según algunas fuentes, por Yakov Protazanov en Crimea, territorio dominado por ese entonces por el ejército "blanco" durante la guerra civil.37 También se incluyeron en esa sección películas alemanas como Noche de espanto (Grausige nachte, Lupu Pick, 1921) y La hija del comediante (Das komödiantenkind, Fred Sauer, 1923). Con la salvedad de La hija del comediante, el resto de las "otras cintas" tampoco respondían a la categoría de estreno. En ninguno de los casos las publicidades ni los comentarios de la prensa especificaban el país de producción de estas películas, por lo que cualquier lector bien podría suponer que también se trataban de films de origen soviético.

Por último, Russ Film incorporó cortometrajes cómicos de procedencia estadounidense, entre ellos algunos de Charles Chaplin. ${ }^{38}$ Seguramente el objetivo era, por un lado, diversificar un programa cinematográfico caracterizado por una inmensa mayoría de films dramáticos y, por otro, que esos cortos oficiaran de comple-

32 En el festival Il Cinema Ritrovato de 2017 fue exhibida una copia incompleta del film.

33 Crítica, 5/2/1924.

34 Por ejemplo, El padre Sergio fue estrenado por la distribuidora nacional Moss y Cía. a comienzos de septiembre de 1921.

35 Ver publicidad en La película, $n^{\circ} 418,25 / 9 / 1924$

36 Este film fue proyectado en el Festival de Cine Mudo de Pordenone de 2003.

37 Ver programa Le giornate del cinema muto, XXII edizione, octubre del 2003.

38 Por ejemplo, en una exhibición se mencionan los cortometrajes Carlitos aristócrata [The count, 1916] de Chaplin y otros denominados Gripe de grupo y Cómo se aprende a nadar, cuyos títulos originales no hemos podido determinar. 
mento de los largometrajes en las funciones de los cines.

De este conjunto de películas distribuidas por Russ Film, en la actualidad sólo son accesibles para su visionado Alma de mujik y El padre Sergio. Sin embargo, a partir de un relevamiento exhaustivo de las reseñas, gacetillas y publicidades de las revistas cinematográficas de la época (Excelsior, La película, Imparcial film y Revista del exhibidor) y de los periódicos de organizaciones políticas y sindicales (La internacional, El libertario y Bandera proletaria) hemos podido reconstruir información sobre el contenido y los rasgos estilísticos de estos films.

\section{Las "veladas" culturales}

La Russ Film no limitó la distribución de sus películas al circuito comercial, sino que planificó también su exhibición en un circuito alternativo.

Tanto el periódico comunista La internacional ${ }^{39}$ como el diario de tendencia anarco-bolchevique El libertario (1923-1932) ${ }^{40}$ publicaron entre fines de agosto y comienzos de septiembre de 1923 la noticia de que la Russ Film "ofrece sus primeras producciones cinematográficas en condiciones ventajosas a bibliotecas, instituciones obreras, sindicatos, etc.". Efectivamente, las producciones de la Russ Film pasaron a formar parte del programa cinematográfico de las veladas artísticas que realizaban diferentes organizaciones políticas de izquierda y obreras con el objetivo de recaudar fondos y de realizar "propaganda". Esas veladas se organizaban en una sala de cine, generalmente en horario nocturno y, además de proyectarse películas, se dictaban conferencias, se recitaban poesías, se interpretaban monólogos y se entonaban canciones militantes. La exhibición de films en esas veladas tendía, por ese entonces, a reemplazar a las tradicionales representaciones teatrales, o bien a establecer una alternancia con ellas. En la mayoría de los casos, Russ Film suministraba el programa cinematográfico completo de esas veladas, y no una película aislada. Por esta razón los films documentales y de ficción de "carácter social" podían ir acompañados de cortometrajes cómicos y/o de las "otras cintas" complementarias que comercializaba esta empresa. Como las organizaciones políticas y sindicales debían pagar a las empresas comerciales por el alquiler de la copia de una película, Russ Film introdujo la posibilidad de que a través de ese pago se pueda colaborar además con una causa política. ${ }^{41}$

\section{La internacional, 26/8/1923.}

40 El libertario, 10/9/1923.

41 Un comentario publicado en Bandera proletaria (18/9/1926) permite confirmar que las organizaciones le abonaban a la Russ Film por la exhibición de las películas, ya que en ese periódico sindical se denuncia al empleado de un gremio por no haber realizado el pago correspondiente a dicha distribuidora.
Desde luego, las películas soviéticas de la Russ Film ocupaban un lugar central en las veladas o funciones cinematográficas organizadas por los centros del Partido Comunista. Por ejemplo, en la primera mitad de 1924 esas exhibiciones se concentraron en aquellas regiones donde tenían su radio de acción las filiales de la Russ Film: La provincia de Buenos Aires y Santa Fe.42

Seguramente la exhibición de estas cintas, por su carácter de novedad, generó una enorme atracción en los militantes o simpatizantes comunistas, mucho más en localidades remotas. Por ejemplo, una crónica de la proyección Un poco de luz sobre la Rusia roja en Roberts (Santa Fe) menciona que pese a la lluvia "es de aplaudir el sacrificio hecho por varios compañeros de Pasteur que vinieron a ésta para ver la cinta de una distancia de 7 leguas y otros de más".43 Ese entusiasmo se materializó durante la proyección ya que "al aparecer la figura de nuestro genial compañero Nicolás Lenin fue recibido con una salva de aplausos siguiéndose en varios pasajes de la cinta, especialmente en el juramento de la bandera roja, por los soldados rojos". 44 Es que muy posiblemente haya sido la primera vez que esos militantes pudieron acceder a una impresión tan vívida, en movimiento, de la vida en la Rusia comunista y de sus líderes. Seguramente la intensa emotividad de la velada también estuvo marcada por el lugar ya mítico que ocupaba Lenin debido a su fallecimiento ocurrido unos pocos meses antes.

También, estas películas tuvieron un lugar central en los festivales realizados por los Comités de Ayuda Obrera con el objeto de recaudar fondos, esta vez, para Alemania. Por ejemplo, el Comité Femenino Pro Ayuda a los niños alemanes exhibió el 22 de marzo de 1924 en Remedios de Escalada (provincia de Buenos Aires) el documental Volga y el film de ficción El ordenanza, velada que fue acompañada de una conferencia sobre "La solidaridad obrera internacional". A su vez, el Comité Local de Ayuda Obrera Internacional de Posadas (Misiones) organizó el 29 de marzo con el mismo fin la proyección de Un poco de luz sobre la Rusia roja.

Sin embargo, las primeras exhibiciones gestionadas por la Russ Film se realizaron en las veladas organizadas por los sindicatos en diversas localidades, especialmente aquellos que formaban parte de la Unión Sindical Argentina (USA). Esta central obrera había sido creada en 1922 bajo la doctrina sindicalista del "apoliticismo", pero en su seno interactuaban, no sin conflictos, diversas tendencias como el sindicalismo revolucionario, el Partido Comunista, los anarco-bolcheviques y los socialistas.

Por ejemplo, el periódico de la Unión Sindical Argentina Bandera

42 Por ejemplo, se proyecta el programa de Russ Film el 13 de enero de 1924 en el Centro Comunista de Lomas de Zamora, el 20 de febrero en Chacabuco, el 23 de marzo en Roberts, el 10 de abril en la ciudad de Santa Fe, el 11 de abril en Rosario y el $1^{\circ}$ de mayo en Alcorta.

43 La internacional, 3/4/1924.

44 Ibídem. 
proletaria (1922-1930) anunció para el 21 de noviembre de 1923 la realización de una velada patrocinada por el Comité Pro Defensa Sindical en el cine-teatro La Paloma de Firmat (Santa Fe), donde se exhibió El milagro del soldado Iván que "envió la Russ Film" junto con el monólogo "Huelga de Herreros", y una conferencia sobre la Revolución Rusa a cargo del militante anarco-bolchevique y delegado de la USA A. Goncalvez. ${ }^{45}$ Posteriormente, las películas se proyectaron en diciembre de 1923 en el marco de un mitin del Sindicato de Sastres en Capital Federal, a mediados de enero de 1924 en un festival del Sindicato de Empleados de Comercio en Capital, el 5 de julio en una velada organizada por el Sindicato de Oficios Varios del partido de González Chávez (Prov. de Buenos Aires) y el 6 de julio en Tres Arroyos. El hecho de que las producciones de la Russ Film se exhibieran en organizaciones obreras no es casual, ya que en su mayoría constituían espacios, como el de la Unión Sindical Argentina, donde se buscaba fomentar la adhesión y la solidaridad hacia el proceso bolchevique por parte del sujeto revolucionario por excelencia del marxismo, el proletariado, y donde intentaban ejercer hegemonía política sectores partidarios de la Revolución Rusa como el Partido Comunista Argentino y los anarco-bolcheviques. En este sentido, es importante destacar que dichas exhibiciones se inscribían dentro de la estrategia del Frente Único Obrero adoptada en esa época por el Partido Comunista.

También la Russ Film logró exhibir, aunque un poco más tardíamente, sus films en los festivales de otras tendencias políticas de izquierda, incluso de aquellas enfrentadas al Partido Comunista y críticas de la experiencia bolchevique, como el anarquismo. Por ese entonces, la mayor parte de las tendencias ácratas en Argentina se oponían a la modalidad de construcción política del bolcheviquismo porque la consideraban autoritaria, descreían de la "dictadura del proletariado" como una supuesta etapa de transición hacia una sociedad sin clases y sin Estado, y denunciaban la represión contra el movimiento anarquista en Rusia.

Por ejemplo, el diario ácrata La antorcha (1921-1932) anunció para el 7 de noviembre de 1925 en el cine Libertad (Rosario) una velada auspiciada por el Grupo de Ayuda y Difusión a la prensa anarquista, donde se programó la exhibición de Alma de mujik, junto con una conferencia del militante Rodolfo González Pacheco y "cantos revolucionarios" a cargo de Martín Castro. ${ }^{46}$ Al año siguiente, se informó de la proyección de El milagro del soldado Iván y Alma de mujik en una función organizada el 11 de septiembre en favor de los presos sociales en Alcorta (Santa Fe), acompañada de una conferencia del militante anarquista y antimarxista Gastón Leval.47

Por otro lado, en noviembre de 1928, en una velada organiza-

45 Bandera proletaria, 24/11/1923.

46 La antorcha, 30/10/1925, p. 3.

47 Ver Bandera proletaria, 4/9/1926. da en la sede del Partido Socialista Italiano en Capital Federal a beneficio de las víctimas del fascismo, se proyectó El diputado morfinómano. ${ }^{48}$

\section{El cine como campo de lucha ideológica}

Ahora bien, la distribución de películas por parte de la Russ Film tanto en las salas comerciales como entre las organizaciones políticas y sindicales no sólo tenía una finalidad económica, sino, esencialmente, político-militante. De hecho, el propio fundador de Internationale Arbeiter-Hilfe (IAH), Willi Münzenberg, en su folleto Erobert den film! hacía un llamado urgente para que los militantes comprendieran el poder del cine y lo utilizaran como un nuevo medio de agitación y propagación de las ideas comunistas, ya que posibilitaba, en muchos casos, el acceso a una mayor cantidad de personas que los periódicos, afectaba al público de una manera más intensa y vívida que la palabra escrita, e incluso lograba trascender las barreras idiomáticas y el analfabetismo. Más aún cuando el cine, por ese entonces, había adquirido una gran popularidad a nivel mundial, y en Argentina se había convertido en uno de los ocios culturales principales de la sociedad. En cierta forma, el cine permitía modernizar las formas de propaganda características de la izquierda, signadas por la palabra escrita (el periódico, el folleto y el libro) y el discurso oral (el mitin político y la conferencia).

Es así que las propias gacetillas publicadas en la prensa de izquierda dieron cuenta de esa finalidad política, al señalar que "la exhibición de estas cintas [...] sirven para contrarrestar la propaganda perniciosa que por intermedio del arte cinematográfico realiza la burguesía" ${ }^{49}$ Una de esas formas que adoptó esa "propaganda perniciosa" es la visión negativa sobre la revolución bolchevique y sobre el marxismo en gran parte del cine de la época. Es por ello que, por ejemplo, el Centro Comunista de Lomas de Zamora convocó a los compañeros a asistir a la proyección de los documentales de la Russ Film señalando que "en los cines de Talleres y de Banfield se exhibieron películas denigrantes para la Rusia Sovietista".50 Precisamente, en el circuito de exhibición nacional durante 1923 y 1924 podemos encontrar una serie de películas de ficción con un claro contenido anti-bolchevique. Es el caso del film estadounidense Bavú (1923, Stuart Paton), estrenado en agosto de 1923, donde "se ve la patria de Lenin bajo el incendio revolucionario de las ideas extremistas". ${ }^{51}$ Su argumento era presentado en la prensa de la siguiente forma:

48 Ver L' Italia del popolo, 22/11/1928. Si bien Russ Film cerró sus puertas en 1927, sus películas continuaron comercializándose por intermedio de la distribuidora Osnola Films.

49 La internacional, 26/8/1923

50 La internacional, 13/2/1924.

51 Excelsior, $n^{\circ} 491,8 / 8 / 1923$ 
En la ciudad mencionada [Belta] estableciose un gobierno revolucionario, cuya primicia disputábanse dos partidos; uno encabezado por Mischka Vieck, revolucionario de ideales y el otro por Bavú, persona inculta que encabezaba el populacho y que deseaba matar y robar para satisfacer sus bajos instintos. $^{52}$

Demás está decir que el barbudo Bavú simbolizaba en el film a los bolcheviques.

Otra película que puede encuadrarse dentro de esta tendencia, si nos atenemos a su publicidad, es la producción europea, estrenada en octubre de 1923, Bajo el látigo del terror,53 que narraba "el calvario del soviet, hundido en los abismos de la miseria de la guerra y del hambre". ${ }^{54}$ Entre mayo y julio de 1924 se anunciaron dos películas que alertaban sobre la infiltración comunista en Estados Unidos, El derecho de la felicidad (The right to happiness, Allen Holubar, 1919), donde se denunciaban "las matanzas en Rusia, el fracaso moral del bolseviquismo", 55 y El apóstol rojo (The stranger's banquet, Marshall Neilan, 1922).

Sin embargo, el concepto de que las películas de la Russ Film "sirven para contrarrestar la propaganda perniciosa que por intermedio del arte cinematográfico realiza la burguesía" trasciende, sin duda, a aquellos films específicos de carácter anti-bolchevique. Desde esta perspectiva marxista el cine al ser, en general, propiedad de la burguesía, terminaba por proyectar su ideología sobre un amplio espectro del público, entre el que se encontraba el sujeto revolucionario: el proletariado. De hecho, el folleto Erobert den film!, escrito en 1925 por Münzenberg llevaba como encabezado la siguiente cita del dirigente principal de la Internacional Comunista Zinóviev: "el cine, propiedad de la burguesía, es el medio más fuerte para engañar a las masas populares. En nuestras manos, el cine puede y debe convertirse en el arma poderosa de la propaganda comunista y la educación de las más amplias masas de trabajadores". Por lo tanto, en reacción a un cine burgués, Russ Film buscó construir a través de la distribución de películas, como lo había hecho la Internationale Arbeiter-Hilfe $(\mathrm{IAH})$ en Alemania, un cine para el proletariado. ${ }^{56}$ De ahí, el interés por exhibirlas comercialmente con el objeto de llegar a un público masivo y de alcanzar al sector proletario a través de la exhibición de películas en los sindicatos y en las organizaciones políticas de izquierda. Así el cine terminaba por formar parte de un proyecto cultural más amplio propugnado por el Partido Co-

52 Excelsior, $n^{\circ}$ 492, 15/8/1923, p. 31.

53 No hemos podido identificar el título original del film.

54 Excelsior, $n^{\circ} 499,3 / 10 / 23$, p. 11.

55 Publicidad en La película, $n^{\circ} 399,15 / 5 / 1924$.

56 Internationale Arbeiter-Hilfe financiará la producción de películas específicamente proletarias en Alemania, y coproducirá films soviéticos a través de la empresa Mezhrabprom-Rus. munista argentino en la década de 1920: la construcción de una cultura proletaria. Como señala Hernán Camarero, en el marco de la estrategia del "frente único", el Partido Comunista buscó fomentar a través de la recreación y la educación del proletariado una cultura obrera alternativa al "ocio alienado", que forjara una identidad y una conciencia de clase proletaria. En pos de ese objetivo se organizaban las veladas culturales o se fomentaba la creación de bibliotecas, centros culturales, órganos de prensa, escuelas obreras y la realización de deportes. ${ }^{57}$

En diversas exhibiciones dentro del espectro político y sindical se explicitaba esta intencionalidad recreativa-educativa. Por ejemplo, Bandera proletaria informó que en una función el conferencista hizo "el elogio sobre la labor de emancipación y la influencia que ejercen sobre las multitudes ansiosas de enseñanzas esta clase de cintas" ${ }^{158}$ y La internacional transcribió el comentario de un obrero en el marco de una velada: "Estas son las cintas que educan y se pueden ver y no las que dan todos los días en los cines. ¡Ojalá Rusia pueda inundar el mundo con su industria cinematográfica, qué grandes serán los beneficios para el proletariado!"59. Es que el cine para el proletariado debía tener un contenido educativo que lo esclareciera en su lucha de emancipación, que lo liberara del engaño del cine burgués. Ese carácter pedagógico se desprende de algunos de los títulos de los films, tanto en un sentido literal (Cómo se educan los niños en Rusia) como en el hecho de "iluminar" sobre una cuestión determinada (Un poco de luz sobre la Rusia roja).

No casualmente, las películas principales de la Russ Film son promocionadas en las propias publicidades de la empresa como "cintas de carácter social", como obras que abordan problemáticas sociales, como veremos, desde un punto de vista específicamente bolchevique o bien desde una perspectiva "denuncialista" más amplia. Es decir, hay una acentuación sobre el contenido de los films en la oferta de la Russ Film.

Sin embargo, esa serie de películas presentan también diferencias. Los documentales, como es característico del género, establecían una relación directa con la actualidad, con el presente histórico, en la medida que abordaban distintos aspectos de la vida dentro del proceso revolucionario en la Unión Soviética. El carácter pedagógico de estos films se manifiesta en el hecho que informan y dan a conocer al espectador los diversos aspectos de la implementación del modelo socialista. Y a su vez, promueven a través de su carácter propagandístico una ideología política que es presentada como liberadora para el proletariado, o bien la acción del Estado soviético y de organizaciones como Comité Internacional de Ayuda a Rusia, que debe ser apoyada y eventualmente imitada.

57 Hernán Camarero, "El Partido Comunista argentino y sus políticas en favor de una cultura obrera en las décadas de 1920 y 1930", en Pacarina del Sur, Ciudad de México, n 7, abril-junio de 2011.

58 Bandera proletaria, 24/11/1923.

59 La internacional, 17/4/1924. 
Ahora bien, para que ese carácter propagandístico tenga efectividad debe corresponderse con una forma de exhibición adecuada. Un caso sintomático lo constituye Volga, una película sobre la hambruna que azotó a Rusia en 1921. Este documental que contenía "cuadros e impresiones recogidas [...] en la región del hambre por la Comisión de Socoro"60 no fue promocionado durante 1924 en la oferta de Russ Film en las revistas cinematográficas destinadas a los dueños de las salas ${ }^{61}$ y sí, en cambio, fue incluido en las publicidades que esta distribuidora publicó en la prensa de izquierda. ${ }^{62}$ Posiblemente la exhibición comercial de este film que había sido realizado con el objeto recaudar fondos dentro del proletariado mundial para paliar el hambre y fomentar la reconstrucción de Rusia podría resultar, por su temática, contraproducente para la imagen de la Unión Soviética en el exterior. Sobre todo, porque se trataba de una tragedia que para 1924 ya se había superado. En cambio, logramos determinar que ese año fue proyectado en funciones organizadas por el Comité Central de Ayuda a Alemania dentro de un marco de exhibición dominado por sectores militantes y sindicales, y por conferencistas que podían eventualmente otorgar el marco "correcto" a la situación descripta por el film.

Por su parte, las ficciones, en su totalidad, se inscribían argumentalmente en el pasado histórico, previo a la revolución. Aquí el "carácter social" de los films, si bien coincidía con aspectos de la ideología comunista, no constituía una propaganda explicita. Tomemos como ejemplo el argumento de las dos películas de ficción principales de la Russ Film. El drama realista psicológico Alma de mujik narraba la historia de un campesino pobre a quien sus amos le encomiendan entregar un sobre con dinero en un pueblo lejano, pero en el camino lo pierde accidentalmente y al regresar, desesperado, se suicida. Paralelamente, el film mostraba la desesperación de los campesinos cuando eran obligados a convertirse en reclutas del ejército del zar.

La comedia dramática El milagro del soldado Iván contaba la vida de un joven campesino que es forzado a realizar el servicio militar, mientras su familia padece las consecuencias de una mala cosecha. Cuando a Iván se le encarga custodiar en el cuartel la imagen de un santo adornado con gemas, roba una de ellas para beneficiar a su familia y anuncia que la Santísima Trinidad se la ha regalado. Luego de ser encarcelado, comienza a circular la noticia de que se produjo un milagro y las mujeres de los oficiales y de los altos funcionarios piden que sea liberado. A pesar de que

60 Publicidad en La internacional, 4/1/1924.

61 Ver, por ejemplo, las publicidades que dan cuenta de un listado más completo de films en La película, $n^{\circ} 418,25 / 9 / 1924$ y en Excelsior, $n^{\circ}$ $520,27 / 2 / 1924$. Tampoco es mencionado en un comentario que incluye la lista de nuevas producciones incorporadas por la empresa en 1924; ver: Excelsior, $n^{\circ}$ 520, 27/2/1924.

62 Ver publicidad en La internacional, 4/7/1924. En contraposición, el aviso publicitario del mismo período publicado en la revista del gremio cinematográfico Excelsior, $n^{\circ} 520,27 / 2 / 1924$, menciona los mismos films, con la excepción de Volga. el clero y el ejército saben de la falsedad del supuesto milagro, deciden darle la libertad y un obsequio a Iván, el hacedor de milagros, para contentar a los fieles.

Tanto Alma de mujik como El milagro del soldado Iván ofrecían una mirada crítica del antiguo régimen, ya sea denunciando la situación de miseria y de servidumbre del campesinado frente al terrateniente, su movilización forzada por parte del ejército del zar, o la mentira religiosa sostenida por el clero y los militares. En ambos casos, se trataba de un cuestionamiento a los estamentos del régimen zarista (iglesia, terratenientes y militares); es decir, hacia un pasado injusto que el presente, la revolución bolchevique, se encargó de aniquilar.

También Russ Film incorporó películas realizadas con anterioridad a la revolución bolchevique como El padre Sergio y Basta de sangre por su claro contenido progresista. La primera cuestionaba la hipocresía y la inmoralidad de la aristocracia zarista y desmitificaba la religión al evidenciar la psicología torturada y los impulsos sexuales reprimidos de un sacerdote que era venerado como un santo, mientras que la segunda exaltaba las rebeliones contra el régimen zarista y denunciaba la brutal represión que ejercía. ${ }^{63}$

El hecho de que este conjunto de films no se inscriba en el presente histórico de la revolución y que posea un contenido de crítica social fue determinante para que puedan ser exhibidos por otras tendencias políticas de izquierda. Es el caso del anarquismo más ortodoxo, que incluyó en sus veladas las ficciones Alma de mujik y El milagro del soldado Iván que, por su contenido antirreligioso o contrario al militarismo y a la servidumbre, coincidían con aspectos del ideario ácrata. Y, por el contrario, en ese espacio político jamás se exhibió ninguno de los documentales propagandísticos de la Russ Film que daban cuenta del presente revolucionario.

Ahora bien, algunas veces, en las exhibiciones realizadas en las veladas, ese "carácter social" y pedagógico era acentuado o complementado a través de la intervención de los conferencistas, presentadores $y$, probablemente, de los propios militantes durante las proyecciones. Por ejemplo, en una función de El milagro de soldado Iván realizada en Formosa se menciona que "E. Rigamonti hizo un breve comentario sobre la cinta que se iba a exhibir, haciendo ver que [...] la virgen no hizo ningún milagro [...] El Santo Sínodo, si admite el robo del soldado Iván como un

63 Yola, la quinta obra de ficción de "carácter social", es imposible de visualizar. Con respecto a su argumento Excelsior, n 514, 16/1/1924, señala que "el drama se desarrolla alrededor de Yola, casada con el conde Kuno, rudo militar que no sabe apreciar la dulzura del corazón femenino de su esposa. Kuno parte como cruzado a combatir a los infieles y Yola no encuentra consuelo ni en la música, ni en las plegarías de su alma mística". Sin embargo, de su lectura resulta muy difícil determinar la orientación ideológico-política, más allá de una posible crítica tangencial al militarismo encarnado en el marido de la protagonista. 
milagro no es más que con el fin de perpetuar la ignorancia del pueblo". ${ }^{64}$ No deja de llamar la atención la necesidad de establecer una lectura unívoca del film entre los espectadores, incluso antes de su proyección, con el objetivo de neutralizar cualquier interpretación que se aparte de un mensaje antirreligioso. En otros casos, las conferencias servían para ampliar el tema abordado por un film, como ocurría con la proyección en Lomas de Zamora de Cómo se educan los niños en Rusia, acompañada de una exposición sobre "La educación cultural de los niños en la Rusia Proletaria" a cargo de Ida Bondareff, o bien funcionaban como complemento del film, como es el caso de la exhibición de una película sobre la hambruna en Rusia, Volga, junto con una conferencia sobre "La solidaridad obrera", que justamente ayudó a paliar esa necesidad.

La conjunción entre el cine y la conferencia no es casual, ya que ambos operan con la misma finalidad: educar, esclarecer y adoctrinar al espectador.

\section{El cine como arte}

Por último, nos proponemos reconstruir la visión del cine que proyectan las películas de ficción principales de la Russ Film a través del análisis de sus publicidades y de las gacetillas en la prensa gráfica.

La mayoría de las obras de ficción establecían una relación explicita con la literatura rusa, en especial con la obra de León Tolstoi. Tres de las cinco películas que se incluían en la oferta principal de "cintas de carácter social" para los exhibidores fueron presentadas como una adaptación de textos de este autor. Así, Alma de mujik era promocionado como "un intenso drama de León Tolstoi", 65 El padre Sergio "de Tolstoi", 66 y El milagro del soldado Iván "por León Tolstoi", 67 a pesar de que este último film nada tenía en común con la obra de este escritor.

Russ Film optó por remarcar la filiación de las películas con este autor ruso seguramente con la intención de potenciar la comercialización de las primeras películas soviéticas en el exterior, ya que la obra de Tolstoi era conocida en occidente y en nuestro país a través de ediciones de libros y de folletos, o bien por medio de su publicación en periódicos y revistas culturales en las primeras décadas del siglo XX.

También es importante remarcar que Tolstoi era, junto con Zola, Víctor Hugo o Gorki, una de las figuras centrales de la literatura

\footnotetext{
64 Bandera proletaria, 23/5/1925.

65 Publicidad en Excelsior, $n^{\circ}$ 517, 6/2/1924

66 Excelsior, $n^{\circ}$ 520, 27/2/1924.

67 Publicidad en Excelsior, n 510, 19/12/1923.
}

social promovida por los sectores de la izquierda argentina, por lo que un film basado en alguna de sus obras resultaba atractivo para las veladas cinematográficas organizadas por las diversas tendencias. En este sentido, podemos entender la incorporación de las obras de la Russ Film dentro de la esfera del anarquismo, donde se exhibieron las obras de ficción basadas en Tolstoi ya que los anarquistas lo consideraban uno de los suyos. ${ }^{68}$

Finalmente, es importante subrayar que esta figura literaria se constituyó prácticamente en el único indicio de autoría artística de los films. ${ }^{69}$ A pesar de que Tolstoi no tuvo ningún tipo de intervención en estas películas, su nombre tiende a predominar, por ejemplo, en las publicidades, por sobre los rubros cinematográficos más relevantes en esa época como la producción, la actuación y la dirección.

Por otro lado, se remarcaba, en los avisos publicitarios y en los comentarios de las películas de Russ Film, su relación con el teatro. Así se mencionaba que Yola es "interpretado por los artistas del gran Teatro de Arte de Moscú", ${ }^{70}$ que en Alma de mujik "interpreta el rol de importancia el extraordinario Moskvin, del Gran Teatro de Arte de Moscú", ${ }^{71}$ y que en Basta de sangre "interpretan los roles de importancia notables actores del gran Teatro de Arte de Moscú" 72 De esta manera, se establecía una relación intrínseca del cine ruso con artes legitimadas como la literatura y el teatro, con referentes literarios y teatrales de cierta relevancia, que servían para prestigiar al nuevo medio cinematográfico como hecho artístico. Esta concepción del cine de ficción nada tenía de innovadora a comienzos de la década de 1920, ya que poseía cierta semejanza con el film d' art, una tendencia que surgió a fines de la primera década de siglo $X X$ y que buscaba legitimar al cine como arte a través de su relación con disciplinas artísticas tradicionales. Tampoco resultaba innovador el estilo de estos films, ya que, si bien las producciones de la Russ Film expresaban un contenido social crítico diferente al del período cinematográfico zarista lo hacían a través de una estética que se referenciaba en el cine ruso prerrevolucionario. No sólo porque varias de esas películas (Basta de sangre y El padre Sergio) fueron realizadas con anterioridad al triunfo bolchevique o debido a que algunos de los directores provenían del cine de la época zarista (Starewicz), sino porque la obra de algunos de los cineastas de la revolución como Alexander Sanin (Alma de mujik) poseía características del cine anterior: el predominio de

68 De hecho, el título nacional de uno de los films basados en Tolstoi, Alma de mujik, remitía al de una reconocida obra teatral dentro la izquierda argentina como Alma gaucha, del dramaturgo anarquista Alberto Ghiraldo. En ambos casos, se apelaba a tipos característicos de ambos países, el campesino ruso (el mujik), y el gaucho.

69 Ver, por ejemplo, las publicidades en La internacional, 4/1/1924 y en Excelsior, $n^{\circ} 510,19 / 12 / 1923$ y $n^{\circ} 520,27 / 2 / 1924$; y el comentario sobre Las nuevas adquisiciones de la Russ Film en Excelsior, $n^{\circ}$ 520, 27/2/1924.

70 Publicidad en Excelsior, $n^{\circ}$ 520, 27/2/1924

71 Crítica, 7/9/1923. A su vez, el realizador de este film, Alexander Sanin, había tenido una importante trayectoria como director teatral.

72 Crítica, 13/4/1924, p. 11. 
la psicología del personaje por sobre la acción, la presencia de un ritmo lento, los finales trágicos, y la conjunción entre cine y literatura popular. ${ }^{73}$

Por lo tanto, esta primera circulación de la cinematografía soviética en nuestro país se diferencia claramente de la renovación formal y del montaje frenético que asociamos con el cine soviético de vanguardia de los años veinte. El gran impacto de lo nuevo, de un nuevo cine que no necesita ser validado por su relación con la literatura y el teatro, se va a producir con el estreno comercial en Argentina de El acorazado Potemkin, de Sergei Eisenstein, a mediados de la década de 1920.

\section{Epílogo}

El caso de la distribuidora Russ Film fue prácticamente inédito en el continente americano. Argentina fue el único país de América Latina donde se comercializaron las primeras películas soviéticas a comienzos de la década de $1920 .{ }^{74}$ En el resto del continente, su circulación se limitó a Estados Unidos y Canadá ${ }^{75}$ Seguramente resultó determinante el hecho de que para 1922 el Partido Comunista argentino, como señala Piemonte, era "el más numeroso y mejor posicionado de Latinoamérica", ${ }^{76}$ como así también que la Internacional Comunista le comenzara a otorgar al PCA desde 1922 un rol central como vector de la expansión del ideario comunista en Sudamérica por sus vínculos e influencia con los incipientes movimientos de Chile, Uruguay, Brasil, Bolivia y Paraguay, en detrimento de México, que había sido el encargado, en la etapa inicial, de coordinar la actividad comunista en América Latina. $^{77}$

73 Ver Silvestra Mariniello, "El cine ruso antes de la revolución", en Jenaro Talens y Santos Zunzunegui (Coord.), Historia general del cine. Volumen III. Europa 1908-1918, Madrid, Cátedra, 1998.

74 De hecho, varios de los estrenos se efectuaron con pocos meses de diferencia con Europa. Por ejemplo, Un poco de luz sobre la Rusia roja se estrenó en 1923 en Alemania, y en julio de ese año en nuestro país. Alma de mujik se exhibió comercialmente en Alemania en marzo de 1923 y en Argentina durante el mes de agosto.

75 Ver Willi Münzenberg, Erobert den film!: winke aus der praxis für die praxis proletarischer filmpropaganda, Berlín, Neuer Deutscher Verlag, 1925.

76 Al respecto, este autor indica que "según los datos arrojados por el informe que la Comisión de Mandatos le hizo llegar durante la trigésima sesión del V Congreso de la IC a Osip Piatnitsky, el PCA contaba por entonces con 3.500 miembros, la misma cantidad que había presentado al momento de la realización del IV Congreso de 1922. El PC de México, el otro de los partidos comunistas de temprana aparición en América Latina, tenía 1.500 miembros en 1922 y 1.000 afiliados tres años más tarde. Chile informaba 2.000 para ambos períodos, en tanto que Uruguay daba cuenta de 1.000 afiliados en el IV Congreso y 600 en el V Congreso. El PC brasilero se encontraba ilegalizado y su incorporación a la IC todavía no había sido resuelta. El PC de América Central tampoco había sido admitido aún y acusaba apenas 50 integrantes". Víctor Augusto Piemonte, "La Internacional Comunista y su Sección Argentina: discordia entorno del "frente único" a comienzos de la década de 1920", en Izquierdas, Santiago de Chile, $n^{\circ} 19$, agosto de 2014, p. 180

77 Ver: Víctor Jeifets y Lazar Jeifets, "La Internacional Comunista y la iz-
La Russ Film tuvo actividad en el gremio cinematográfico nacional entre 1923 y 1927. Pero su período de mayor actividad se circunscribió de agosto de 1923 a julio de 1924, cuando dicha empresa terminó de delinear su oferta de films. Desde entonces, su programación permaneció inalterable, a pesar de que en reiteradas oportunidades se anunció la inminente incorporación de nuevas producciones soviéticas. ${ }^{78}$ No deja de resultar llamativa la ausencia de novedades en su programación, si tenemos en cuenta que la organización de la que dependía Russ Film, la Internationale Arbeiter-Hilfe, continuó con la distribución de films a nivel mundial durante los años sucesivos. Seguramente esa falta de renovación en la oferta de películas fue determinante para que se convirtiera en una distribuidora cada vez más marginal dentro del circuito comercial. La última información que pudimos recabar sobre la existencia de esta empresa data de 1927, cuando se informó que la distribuidora Osnola Films se hizo cargo de comercializar sus películas bajo la denominación de Programa Russ Film. ${ }^{79}$

De todas formas, Russ Film sirvió de antecedente para un proyecto más ambicioso como fue la constitución en Buenos Aires de una distribuidora de films soviéticos para toda Sudamérica a fines de la década de 1920, que se encargó de comercializar las obras de cineastas fundamentales como Sergei Eisenstein, Kozintsev- Trauberg, Dziga Vertov, Boris Barnet, Yevgeni Chervyakov, Yuri Tarich y Abram Room. Pero se trata de otro capítulo de la historia del cine soviético en Argentina.

quierda argentina: primeros encuentros y desencuentros", en Archivos de historia del movimiento obrero y la izquierda, Buenos Aires, $n^{\circ} 5$, septiembre de 2014. En el mismo sentido, Camarero señala que "con la creación, en 1921, del Buró de Propaganda Comunista para Sudamérica, con sede en Buenos Aires, el PC empezó a ser considerada su sección más poderosa [por parte de la Internacional Comunista], una suerte de representante oficial de la revolución rusa en el subcontinente". Hernán Camarero, "Buenos Aires-Moscú. El Partido Comunista argentino y la Revolución Rusa hasta los años treinta", en Anuario de la Escuela de Historia, Rosario, $n^{\circ} 29,2017$.

78 Por ejemplo, Excelsior, n 643, 9/7/1926, "Diversas Notas...", informó que "la Russ Film acaba de adquirir varias películas de las que filmó últimamente el soviet" y Excelsior, n 680, 25/3/1927, "Diversas Notas..." señaló que esta distribuidora "acaba de firmar contrato con dos importantes productoras rusas".

79 Ver, por ejemplo, las publicidades de Osnola Films en La película, $n^{\circ}$ $565,21 / 7 / 1927$ y en Revista del exhibidor, $n^{\circ} 33,20 / 8 / 1927$. Sin embargo, hemos podido determinar que en 1928 y 1929 algunas de las películas que distribuía Russ Film todavía se exhibían en forma muy aislada en las veladas organizadas por diferentes organizaciones de izquierda. Para el 24 de noviembre de 1928 se anunció la proyección de El diputado morfinómano organizada por la sección Buenos Aires del Partido Socialista Italiano (L'Italia del popolo, 22/11/1928), y para el 30 de abril de 1929 se promocionó la exhibición en Capital Federal de Cómo se educan los niños en Rusia a beneficio del Socorro Rojo Internacional y la Alianza Antifascista Italiana (L'Italia del popolo, 27/4/1929). 


\section{Bibliografía}

Aguilar, Gonzalo y Jelicié, Emiliano, Borges va al cine, Buenos Aires, Libraria, 2010.

Bustelo, Natalia, "Las lecciones de Alfons Goldschmidt en la Reforma Universitaria: economía marxista y radicalización estudiantil (1922)", Actas de las VI Jornadas del Movimiento Estudiantil, 2016.

-"Entre el entusiasmo ante las noticias insurreccionales y la discusión doctrinaria. Las primeras ediciones bolcheviques argentinas (1918-1924)", en Horacio Tarcus (dir.) y Ezequiel Saferstein (ed.), Edición y revolución. Las editoriales de izquierda en Argentina, Buenos Aires, Ubú Ediciones (en prensa).

Camarero, Hernán, "El Partido Comunista argentino y sus políticas en favor de una cultura obrera en las décadas de 1920 y 1930", en Pacarina del Sur, Ciudad de México, $n^{\circ} 7$ abril-junio de 2011.

"Buenos Aires-Moscú. El Partido Comunista argentino y la Revolución Rusa hasta los años treinta" en Anuario de la Escuela de Historia n² 29, 2017.

Tiempos rojos. El impacto de la Revolución rusa en la Argentina, Buenos Aires, Sudamericana, 2017.

Cortell Huot-Sordot, Guido y Darias, Iván, "Las aportaciones expresivas de los directores soviéticos", en Manuel Palacio y Julio Pérez Perucha (Coord.), Historia general del cine. Volumen V. Europa y Asia 1918-1930, Madrid, Cátedra, 1997.

Doeswijk, Andreas L., Los anarco-bolcheviques rioplatenses Buenos Aires, CeDInCl Editores, 2013.

Domínguez Rubio, Lucas, El anarquismo argentino. Bibliografía, hemerografía y fondos de archivo, Buenos Aires, Libros de Anarres, 2018.

Jeifets, Víctor, "La derrota de los 'Lenins argentinos': La Internacional Comunista, el Partido Comunista y el movimiento obrero de Argentina, 1919-22", en Pacarina del Sur, Ciudad de México, n 6, enero-marzo de 2011.

Jeifets, Víctor y Jeifets, Lazar, "La Internacional Comunista y la izquierda argentina: primeros encuentros y desencuentros", en Archivos de historia del movimiento obrero y la izquierda, Buenos Aires, $n^{\circ}$ 5, septiembre de 2014.

Leyda, Jay, Kino. Historia del cine ruso y soviético, Buenos Aires,
Eudeba, 1965

Lucena, Daniela, "Por el hambre en Rusia. Una ofrenda de los artistas argentinos al pueblo de los soviets", en Sociedad, Buenos Aires, $n^{\circ} 26,2007$.

Mafud, Lucio, "La representación del anarquismo y de la protesta social en el cine mudo argentino a través de la prensa periódica (1909-1922)", en Izquierdas, Santiago de Chile, $n^{\circ} 33$, mayo de 2017.

--Entre Rusia y 'Boedo': Los orígenes del documental independiente de crítica social en Argentina", en Imagofagia Buenos Aires, n²1, abril de 2020.

Mariniello, Silvestra, "El cine ruso antes de la revolución", en Jenaro Talens y Santos Zunzunegui (Coord.), Historia general del cine. Volumen III. Europa 1908-1918, Madrid, Cátedra, 1998.

-"Cine y sociedad en los años de oro del cine soviético", en Manuel Palacio y Julio Pérez Perucha (Coord.), Historia general del cine. Volumen V. Europa y Asia 1918-1930, Madrid, Cátedra, 1997.

Moussinac, Léon, El cinema soviético, Madrid, Atheia, 1931.

Münzenberg, Willi, Erobert den film!: winke aus der praxis für die praxis proletarischer filmpropaganda, Berlín, Neuer Deutscher Verlag, 1925.

Piemonte, Víctor Augusto, "La Internacional Comunista y su Sección Argentina: discordia entorno del "frente único" a comienzos de la década de 1920", en Izquierdas, Santiago de Chile, n 19, agosto de 2014, pp. 172-193.

Shull, Michael Slade, Radicalism in american silent films, 19091929: A filmography and history, Carolina del Norte, McFarland, 2000.

Tarcus, Horacio, Diccionario biográfico de la izquierda argentina. De los anarquistas a la "nueva izquierda" (1870-1976), Buenos Aires: Emecé Editores. 2007.

Wells, Sarah Ann, "Parallel modernities?: The first reception of soviet cinema in Latin America", en Rielle Navitski y Nicolas Poppe (Edit.), Cosmopolitan Film Cultures in Latin America, 18961960, Indiana University Press, Bloomington, Indiana, 2017, pp. $151-175$ 


\section{Resumen}

El objetivo de este artículo es estudiar la difusión, a comienzos de la década de 1920, del primer cine soviético en la Argentina, que se realizó a través del Comité Central de Ayuda al Proletariado Ruso, una organización dedicada principalmente a recaudar fondos para paliar la hambruna que azotó a Rusia en 1921 y que constituyó la distribuidora Russ Film. Se trató de la única distribuidora en toda Latinoamérica dedicada a la exhibición de las primeras películas soviéticas que había sido conformada a instancias de la Internationale Arbeiter-Hilfe (IAH), la organización fundada por el dirigente comunista alemán Willi Münzenberg para fomentar la solidaridad social hacia la Unión Soviética y la difusión de las ideas comunistas a nivel mundial. De esta forma, se pudieron conocer en Argentina, por intermedio de la Russ Film, los primeros documentales propagandísticos de la revolución bolchevique y las primeras producciones de ficción soviéticas. Por un lado, estudiaremos el contenido y el estilo de algunos de estos films, y las estrategias de promoción adoptadas para su comercialización por esta distribuidora. Por otro, abordaremos el particular sistema de exhibición implementado por la Russ Film, ya que no solo distribuyó sus películas en las salas comerciales, sino también a través de un circuito alternativo: el de las "veladas" culturales realizadas por las diversas tendencias políticas de la izquierda argentina y las organizaciones sindicales. A pesar de que la mayor parte de esa producción resulta muy difícil de visualizar, o directamente se encuentra perdida, el relevamiento de las revistas cinematográficas de la época y de las publicaciones periódicas de izquierdas permitió obtener información sobre las características de estos films y reconstruir su marco de exhibición.

Palabras clave: Cine soviético; Revolución Rusa; Cine mudo en Argentina; Comité Central de Ayuda al Proletariado Ruso; Russ Film; Partido Comunista argentino; Willi Münzenberg, Internationale Arbeiter-Hilfe.

\section{Abstract}

The objective of this article is to study the diffusion, at the beginning of the 1920s, of the first Soviet cinema in Argentina, which was carried out through the Central Committee for Aid to the Russian Proletariat, an organization dedicated mainly to raising funds to alleviate the famine that struck Russia in 1921 and constituted by the Russ Film distributor. It was the only distributor in Latin America dedicated to the exhibition of the first Soviet films that had been formed at the behest of the Internationale Arbeiter-Hilfe (IAH), the organization founded by the German communist leader Willi Münzenberg to promote social solidarity towards the Soviet Union and the spread of communist ideas worldwide. Thus, the first propaganda documentaries of the Bolshevik revolution and the first Soviet fiction productions could be seen in Argentina, through Russ Film. On the one hand, we will study the content and style of some of the films, and the promotion strategies received for their marketing by this distributor. On the other, we will address the particular exhibition system implemented by Russ Film, since it not only distributed its films in commercial theaters, but also through an alternative circuit: that of the cultural "evenings" held by the various political tendencies of the Argentine left and trade union organizations. Despite the fact that most of this resulting production is very difficult to visualize, or is directly lost, the survey of the film magazines and the left-wing periodicals offered information on the characteristics of these films and reconstructing their framework of exhibition.

Keywords: Soviet cinema; Russian Revolution; Silent cinema in Argentina; Central Committee for Aid to the Russian Proletariat; Russ Film; Argentine Communist Party; Willi Münzenberg, Internationale Arbeiter-Hilfe.

Recibido: 05/07/2020

Aceptado: 10/09/2020. 


\section{ACTUALIDAD SENSACIONAL!!!}

\section{"UII POCO DE LUZ SODPE LA RUSSIR ROJA"}

Primera documentación gráfica sobre la vida de la Rusia actual. Film tomado con motivo de celebrarse el Quinto .Aniversario de la Revolución Bolsheviqui y el Cuarto Congreso de Ia Internacional Comunista.

\section{SUMARIO:}

Petrograd y Moscou. - Las sedes del SovieL. - Ferrocarriles, - El cuarto Congreso de la Internacional Comunista. - EI ejércilo rojo de las Ires armas. - Los dirigentes: Zinovieff, Bujarin, Bela Khun, Radech, Munzembarg, ete. - Una arenga de Trotsky. - La delegación Argenlina. - Los comisarios del pueblo. - La población de las ciudades festejando el Quinto Aniversario de la Revolución, ele., elc..

Por el enorme interés que despertará en el público será un ruidoso éxito de boleteria!

\section{EN 5 GRANDES ACTOS}

\section{Estreno el Viernes 20 del corriente}

\section{PROGRAMA EXTRAORDINARIO}

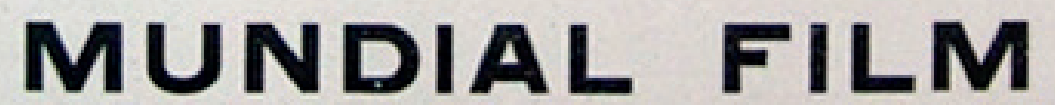

CONCESIONARIOS EXCLUSIVOS: MUNDIAL FILM - MONTEVIDEO 17, Buenos Aires

Fiasles en: CHILE, BOLIVLA, PERU, URUGUAY y PARAGUAY 


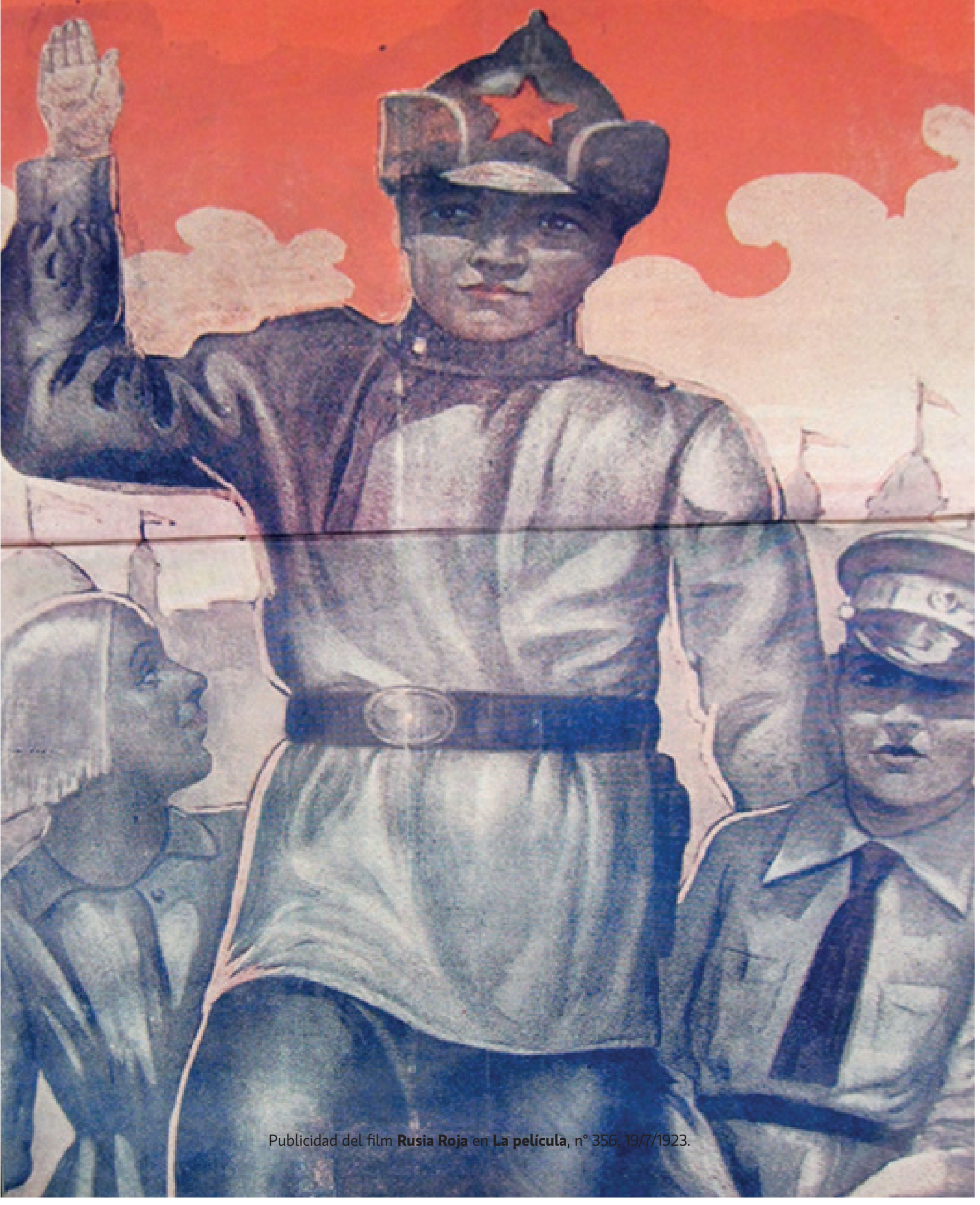

